\title{
Spatial variability assessment of Nile alluvial soils using electrical resistivity technique
}

\author{
Gamal S. Swileam a, Reda R. Shahin a,* , Hamdy M. Nasr a, Khalid S. Essa ${ }^{\text {b }}$ \\ a Department of Soil Science, Faculty of Agriculture, Cairo University, Giza, Egypt \\ b Department of Geophysics, Faculty of Science, Cairo University, Giza, Egypt
}

\section{Article Info}

Received : 09.10.2018

Accepted : 18.02.2019

\begin{abstract}
Spatial information about soils generally results from local observations which are destructive and time consuming. Geophysical techniques could help soil mapping since they are non-destructive and fast. Electrical resistivity is interesting for soil studies due to a wide range of values and as it depends on soil characteristics. This work aims to study soil spatial variability using electrical resistivity. GPS defined grid points of $40 \mathrm{X} 40 \mathrm{~m}$ were installed in the experimental western farm (EWF) in the Faculty of Agriculture of Cairo University in Giza. Electrical resistivity was measured at 40 points using 4-electrodes Wenner array in a line perpendicular to the path direction. Soil resistivity data from 2depths profiling mode was considered to produce two apparent resistivity maps and geostatistically tested. Soil resistivity taxa were sampled and analyzed for soil moisture, EC and bulk density. Krigged soil resistivity maps were produced for depths (i.e. 30 and 60 $\mathrm{cm}$ ). Kriging and Semivariogram interpretation was conducted, and the spatial dependency of top and subsoil resistivity were moderate ( $48.4 \%$ and $68.6 \%$ respectively). Highly significant negative correlations were recorded in the topsoil between apparent or true resistivity and soil moisture, EC or bulk density. The obtained models were used to produce conjugated moisture and EC maps and geostatistically investigated. The spatial dependency of the top and subsoil moisture or salinity were moderate. Soil moisture and EC are the most significant factors for controlling soil electrical resistivity. The method used opens the way to the development of semi-automatic soil mapping from electrical resistivity data.
\end{abstract}

Keywords: Soil resistivity, Wenner profiling, soil moisture, soil salinity, mapping, spatial dependency.

(C) 2019 Federation of Eurasian Soil Science Societies. All rights reserved

\section{Introduction}

Because the huge number of soil sampling and laboratory analysis work required in ordinary survey methods cause waste of time and money, alternative methods to investigate spatial variability of soil properties are desirable. Soil electrical resistivity could be considered as a proxy for the spatial and temporal variability of soil physical and chemical properties (i.e. soil structure, water content, salinity or fluid composition). This non-destructive and sensitive method is a unique tool for assessing the soil subsurface properties without digging (Samouëlian et al., 2005). The electrical resistivity method was applied in different studies such as: groundwater exploration, landfill delineation and solute transfer, agronomical management of soil compaction or soil and water table depths and also soil moisture status assessment.

The electrical resistivity surveys, depending on the soil variability, can be made in 1-, 2- or 3-dimensions and also at different resolutions from small to regional scales. Soil electrical resistivity (ER) is increasingly used in near-surface soil applications because it is related to many soil characteristics and electrical survey

\footnotetext{
${ }^{*}$ Corresponding author.

Department of Soil Science, Faculty of Agriculture, Cairo University, Giza, Egypt

Tel.: +201221039188 e-ISSN: 2147-4249
}

E-mail address: dredashahin@gmail.com DOI: 10.18393/ejss.528851 
information; it therefore, represents a rapid and flexible tool to predict spatial soil variability at the field or local scale (Panissod et al., 1998; Lund et al. 1999; Dabas et al., 2001). The soil bulk electrical resistivity technique offers the following advantages: (i) widely used to characterize soil physical and chemical properties, (ii) ER measurements can be taken quickly, (iii) low cost, (iv) two people can cover a large area, (v) monitoring of soil variability, (vi) exploring soil subsurface without digging and (vii) minimizing the number of soil samples. Soil bulk resistivity depends on multiple variables including soil texture and structure, porosity, soil moisture content (Besson et al., 2010), pore water salinity, temperature and sometimes the presence of root biomass. Several studies have been performed using this technique, with the aim of delineating field zones for managing specific crops in the context of digital agriculture (Heiniger et al., 2003; Kitchen et al., 2003; Corwin et al., 2006), mapping soil texture (Jung et al., 2005; McCutcheon et al., 2006) and describing the soil structure of different soil horizons (Tabbagh et al., 2000) and soil salinity variability (Rhoades, 1993; Omonode and Vyn, 2006).

The objectives of the present study were to: (i) survey the electrical resistivity of an alluvial soil farm using the Profiling Model in two depths to describe its spatial variability, (ii) correlate profiling resistivity values in the alluvial farm with its correspondent physical and chemical properties and (iii) produce the soil map of the studied farm by correlating ER units with their physical and chemical properties.

\section{Material and Methods}

\section{Principals of electrical resistivity measurement}

Electrical resistivity methods introduce an electrical current into the soil through current electrodes at the soil surface and measure the drop in current flow potential at inner electrodes. The Wenner array of electrode configuration was described by four electrodes placed at equal distances in a straight line. The outer two electrodes were working as the current or transmission and the inner two electrodes the potential or receiving ones (Figure 1).

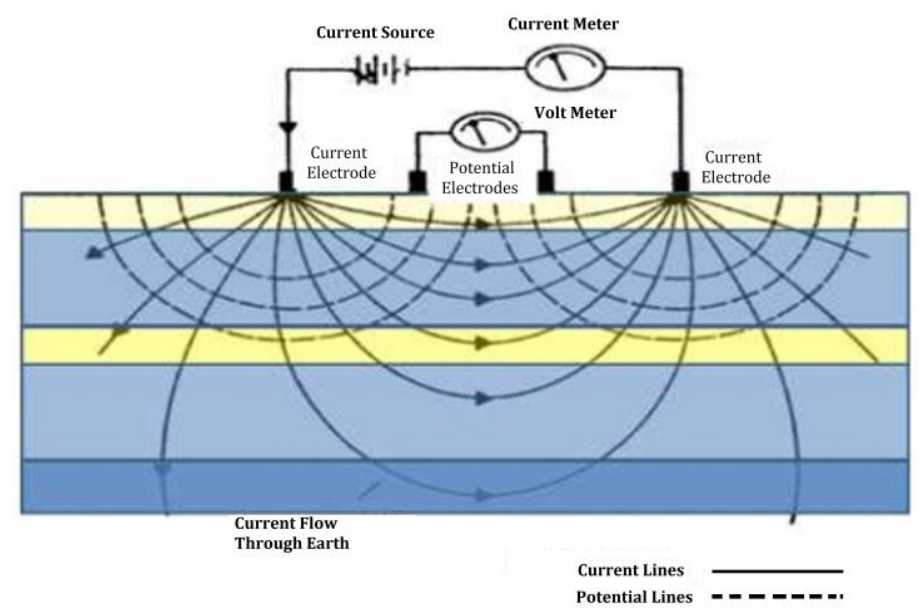

Figure 1. The flow of current and potential line in the measurement of soil electrical resistivity using the Wenner electrod arrayThe extent of electrical current penetration and the depth and volume of measurement depend on the inter electrode spacing. The larger the spacing the deeper the measurement and volume of measurement. The resistivity measured with the Wenner array (Burger, 1992) is:

$$
\rho=2 \pi a \Delta \mathrm{V} / i=2 \pi a R
$$

One and two meters spacing between probes were chosen so as to detect metric contrasts in the soil properties at two depths (US-EPA, 2019). Soil resisitivity readings were converted to apparent resistivity using the relation:

$$
\rho_{a}=k_{i} \frac{\Delta V}{I}
$$

With $\mathrm{i}=1,2 \mathrm{~m}$ for each array and where $\mathrm{I}=\mathrm{is}$ the injected current in $\mathrm{mA}, \Delta \mathrm{V}$ is the electrical potential difference (Volt) measured between electrodes $\mathrm{Mi}$ and $\mathrm{Ni}$ and the geometrical parameter for each array is:

$$
k_{i}=\frac{\pi}{\frac{1}{A M_{i}}-\frac{1}{A N_{i}}}
$$




\section{Site description}

The experimental western farm (EWF) in the Faculty of Agriculture, Cairo University at Giza was chosen for the present study. The geo-referenced coordinates of the investigated rectangle area (@ 6.1 hectares) were shown in Figure 2.

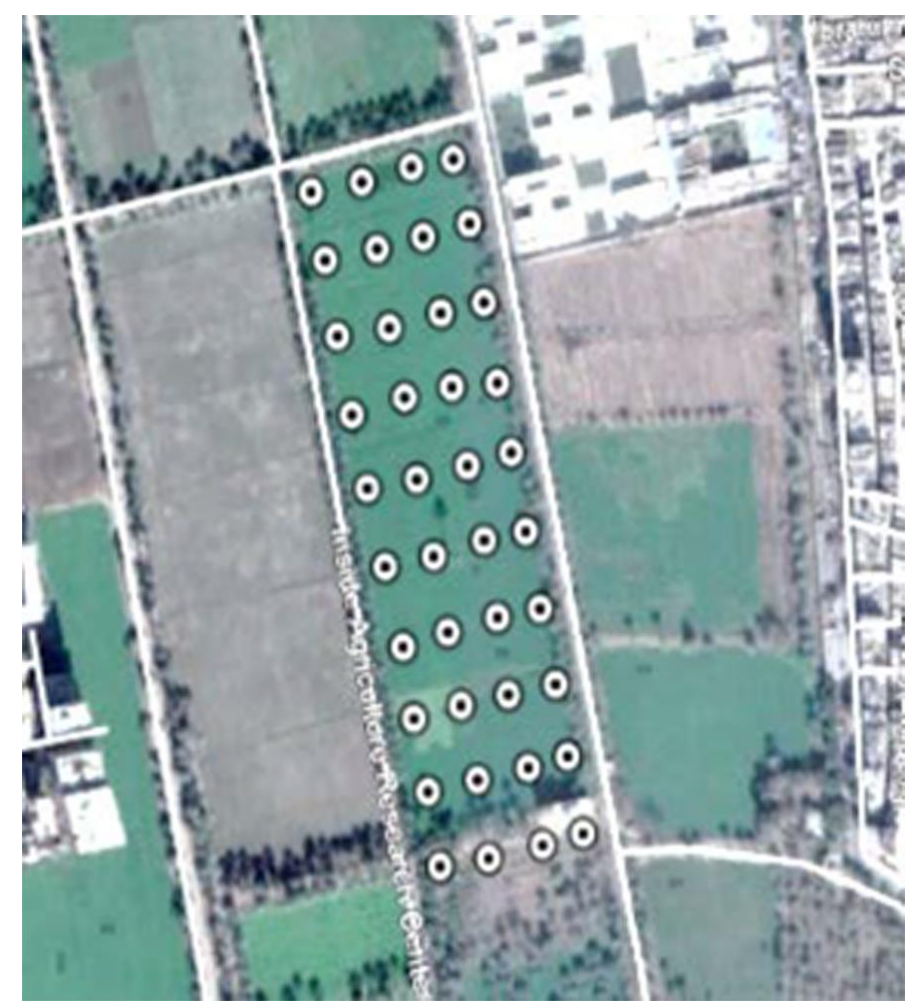

Figure 2. Acquisition of the Resistivity Data

For the farm survey, GPS defined grid points of 40X40m were istalled. Data were acquired on the nodes of regular grids extended across an area of about 160 by $400 \mathrm{~m}$. At each point ( 40 nodes), resistivity was measured using 4-electrodes Wenner array in a line perpendicular to the path direction (Sudha et al., 2009). The readings were collected by a resistivity meter (KYORITSU-KEW-4106). All measurements (40 points) were geo-referenced using a Germin-550 differential GPS and recorded on a PC.

\section{Data preprocessing}

Data processing was simple and consisted of: i) Inversion of the apparent resistivity values (Ra) into true resistivity (Rt) using the IPI2win software, then ii) generating an iso-line distribution map of the inverted electrical resistivity data to report the spatial distribution of the true resistivity values. The maps were generated using the ArcGis Software (ESRI, 2011). The results were presented in the form of two maps corresponding to the two targeted depths of soil layers. These maps represent the contribution of the cumulative soil volume, from the surface down to the two depths of investigation, 0.3 , and $0.6 \mathrm{~m}$ for arrays 1 and $2 \mathrm{~m}$, respectively.

\section{Determination of soil properties}

Ten taxa were identified from the resistivity maps. Composite disturbed soil samples were collected at two depths (0-30 and 30-60 cm) to represent each soil resistivity taxa. The collected samples were analyzed for soil moisture content (Gardner, 1986) and electrical conductivity EC at a 1:2.5 soil:water ratio (Rhoades, 1982). In addition, undisturbed soil samples for each resistivity taxa were collected to determine soil bulk density (Blake and Hartge, 1986).

\section{Results and Discussion}

Soil resistivity values for the surface layers $(0-30 \mathrm{~cm})$ and $(30-60 \mathrm{~cm})$ were mapped using the ArcGis software (ESRI, 2011) and presented in Figure 3. Kriging and Semivariogram Interpretation was conducted to find out the spatial dependency of the top soil (Nugget/sill, \%), and the resultant output was presented in Table 1. The weighted least square method was used to estimate the auto- and cross-variogram parameters (i.e., nugget, sill and range). 
Table 1. The Semivariogram Model interpretation of the surface and subsoil block krigged soil maps of electrical resistivity, moisture and salinity

\begin{tabular}{|c|c|c|c|c|c|c|}
\hline \multirow{4}{*}{$\begin{array}{l}\text { Semivariogram } \\
\text { properties }\end{array}$} & \multicolumn{6}{|c|}{ Soil map property } \\
\hline & \multirow{2}{*}{\multicolumn{2}{|c|}{$\begin{array}{c}\text { Electrical Resistivity } \\
\text { Layer depth }\end{array}$}} & \multirow{2}{*}{\multicolumn{2}{|c|}{$\begin{array}{c}\text { Soil Moisture } \\
\text { Layer depth } \\
\end{array}$}} & \multirow{2}{*}{\multicolumn{2}{|c|}{$\begin{array}{l}\text { Soil Salinity } \\
\text { Layer depth }\end{array}$}} \\
\hline & & & & & & \\
\hline & $0-30 \mathrm{~cm}$ & $30-60 \mathrm{~cm}$ & $0-30 \mathrm{~cm}$ & $30-60 \mathrm{~cm}$ & $0-30 \mathrm{~cm}$ & $30-60 \mathrm{~cm}$ \\
\hline Semivariogram Model type & Spherical & Spherical & Spherical & Spherical & Spherical & Spherical \\
\hline Nugget & 8.889 & 15.013 & 12.899 & 6.163 & 0.038 & 0.071 \\
\hline Range (m) & 137.250 & 137.37 & 138.19 & 159.13 & 86.04 & 151.61 \\
\hline Partial sill & 8.35 & 6.88 & 14.24 & 4.039 & 0.017 & 0.043 \\
\hline Spatial dependency & $\begin{array}{c}48.4 \% \\
\text { (Moderate) }\end{array}$ & $\begin{array}{c}68.6 \\
\text { (Moderate) }\end{array}$ & $\begin{array}{c}47.53 \% \\
\text { (Moderate) }\end{array}$ & $\begin{array}{c}60.41 \\
\text { (Moderate) }\end{array}$ & $\begin{array}{c}48.4 \% \\
\text { (Moderate) }\end{array}$ & $\begin{array}{c}68.6 \\
\text { (Moderate) }\end{array}$ \\
\hline
\end{tabular}
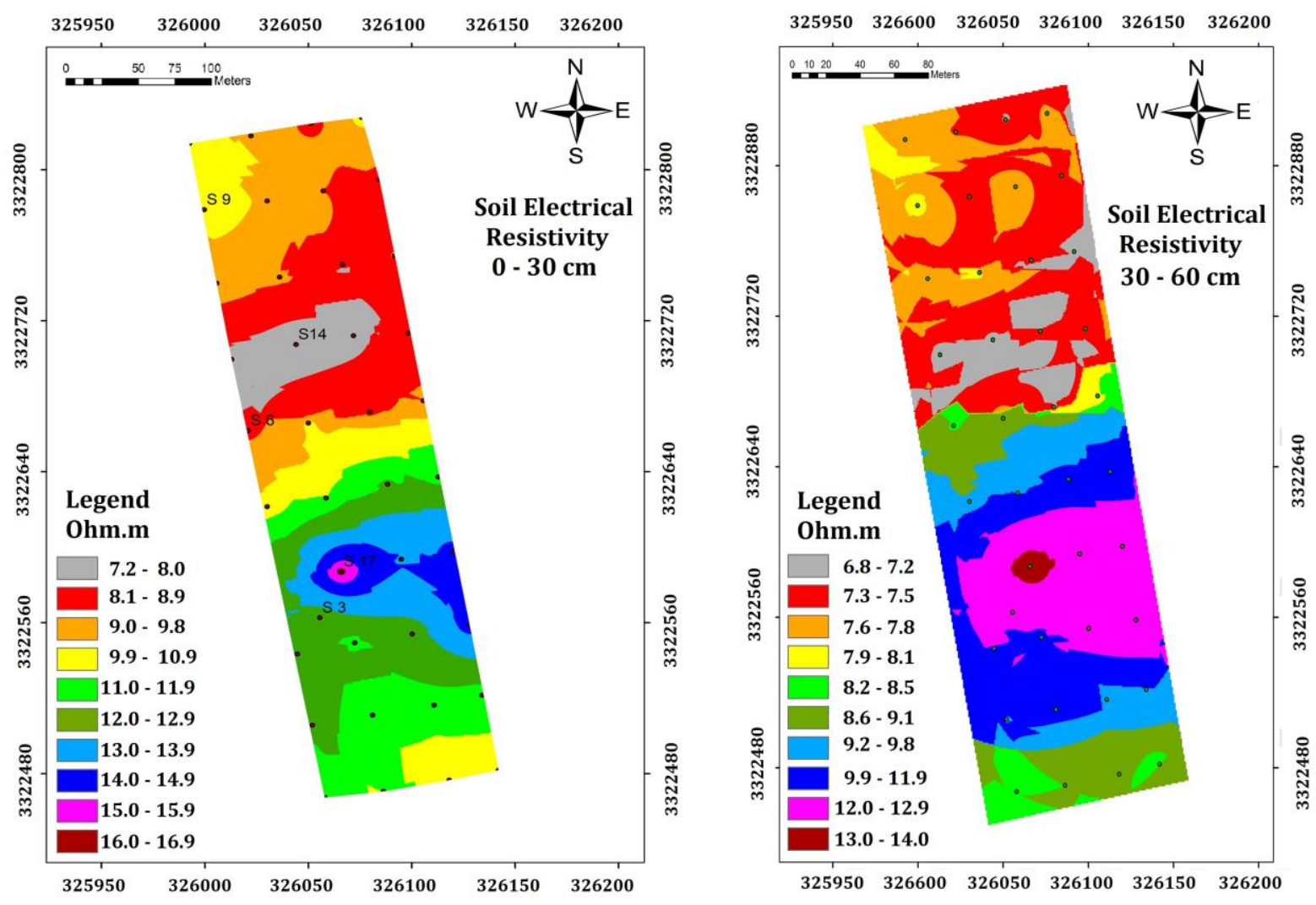

Figure 3. Topsoil $(0-30 \mathrm{~cm})$ and subsoil $(30-60 \mathrm{~cm})$ soil electrical resistivity krigged map

Any soil property has strong spatial dependency if the ratio of nugget/sill is equal to or less than $25 \%$, moderate spatial dependency if between 25 and 75\%, and weak spatial dependency if greater than $75 \%$ (Cambardella et al., 1994; Sun et al., 2003).

From figure 3 and Table 1, it is clear that the spatial dependency of both topsoil and subsoil resistivity is moderate (48.4\% and 68.6\%, respectively). Gülser et al. (2016) stated that strong spatial dependency of soil properties is related to structural intrinsic factors such as texture and mineralogy, while random extrinsic factors such as dynamic moisture and porosity properties showed moderate or weak spatial dependency.

Generally, a semi-variogram may reach its sill at a finite distance called the range. The range of the semivariogram represents the distance limit beyond which the data are no longer correlated, and it was found to be $137.3 \mathrm{~m}$ for the resistivity of the investigated topsoil. Eight soil taxa units were identified to cover the resistivity range between 4 and $24 \mathrm{Ohm}$.m were resulted from the krigged map.

The soil physical properties of the composite soil samples representing the resistivity taxa units of both topsoil and subsoil were shown in Table 1 . The number of sampling sites represented $20 \%$ of the total grid points which were normally sampled in an ordinary soil survey. Simple regression analysis was developed between both apparent/true resistivities and each of the soil moisture content, EC and bulk density. Figure 4 represents the best fitting relationships for each property for both the top- and subsoils. 
Highly significant negative correlations were recorded in the topsoil between apparent or true resistivity and soil moisture, EC or bulk density. The best fitting relationship models (Table 3) ranged between linear, power, logarithmic and exponential models. Weak or insignificant relationships were recorded in the subsoil. These findings indicated that the present array of soil resistivity measurement could be more useful for detecting topsoil variability efficiently. It is suggested future works could focus on the subsoil layer changing the array of soil resistivity measurement. Pandey (2015) observed that the resistivity of sandy soils decreased rapidly with an increase in the water/fluid content, but the rate of decrease dropped considerably for water contents over $10-12 \%$.

Table 2. The apparent and true resistivities, soil moisture content, EC and bulk density of the main topsoil and subsoil resistivity taxa units

\begin{tabular}{|c|c|c|c|c|c|}
\hline Taxa Unit & Apparent $\mathrm{R}(\Omega \mathrm{m})$ & True $\mathrm{R}(\Omega \mathrm{m})$ & $\theta \%(w / w)$ & $\mathrm{EC}_{2.5, \mathrm{dS} / \mathrm{m}}$ & Bulk Density, g.cm ${ }^{-3}$ \\
\hline \multicolumn{6}{|c|}{ Topsoil $(0-30 \mathrm{~cm})$} \\
\hline I & 12.90 & 17.59 & 25.0 & 1.09 & 1.35 \\
\hline II & 9.20 & 10.76 & 26.0 & 0.63 & 1.17 \\
\hline III & 6.20 & 6.36 & 33.7 & 1.48 & 1.24 \\
\hline IV & 4.80 & 5.04 & 31.7 & 0.94 & 1.32 \\
\hline $\mathrm{V}$ & 4.70 & 5.57 & 35.0 & 1.63 & 1.33 \\
\hline VI & 18.00 & 18.16 & 23.5 & 1.33 & 1.18 \\
\hline VII & 24.00 & 20.42 & 23.3 & 1.49 & 1.14 \\
\hline VIII & 14.20 & 15.62 & 30.9 & 1.13 & 1.38 \\
\hline \multicolumn{6}{|c|}{ Subsoil $(30-60 \mathrm{~cm})$} \\
\hline I & 8.00 & 4.11 & 24.0 & 0.89 & 1.36 \\
\hline II & 7.40 & 5.57 & 26.7 & 0.65 & 1.18 \\
\hline III & 6.00 & 5.73 & 33.2 & 1.49 & 1.22 \\
\hline IV & 4.50 & 4.11 & 30.8 & 1.13 & 1.32 \\
\hline $\mathrm{V}$ & 3.70 & 2.72 & 32.2 & 1.61 & 1.30 \\
\hline VI & 17.80 & 17.51 & 21.3 & 1.02 & 1.26 \\
\hline VII & 29.10 & 41.17 & 23.3 & 1.20 & 1.31 \\
\hline VIII & 12.50 & 10.53 & 26.3 & 0.86 & 1.45 \\
\hline
\end{tabular}
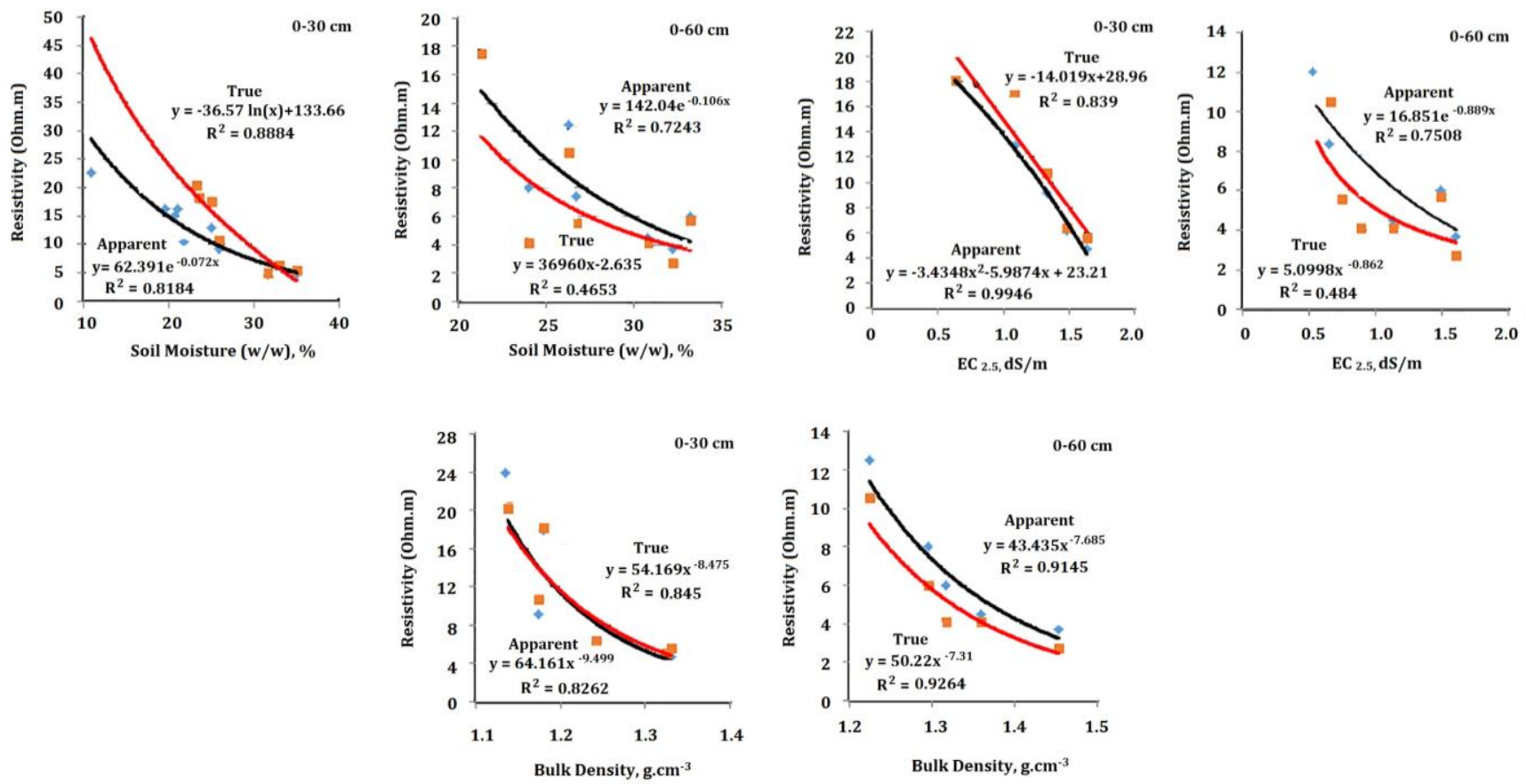

Figure 4. The best fitting relationships for each soil property and apparent or true resistivities for both top- and subsoils

The relationships shown in Table 3 were in good agreement with a great number of studies. In literature, various models were proposed to describe the relationships between electrical resistivity and soil water content, temperature or salt content. Relationships between soil water content and electrical resistivity were measured in field and laboratory conditions and mostly through curvilinear models (Abidin et al., 2013; 
Ozcep et al., 2009, 2010). Kusim et al. (2013) showed that the electrical resistivity decreased significantly by increasing the salt content in the soil.

Table 3. The statistical relationship models between apparent or true resistivities with soil moisture, EC and bulk density for both top- and subsoils.

\begin{tabular}{|c|c|c|}
\hline Soil Property & Apparent Resistivity & True Resistivity \\
\hline \multicolumn{3}{|c|}{ Topsoil } \\
\hline \multirow{3}{*}{ Moisture } & $y=62.391 e^{-0.072 x}$ & $y=-36.57 \ln (x)+133.66$ \\
\hline & $\mathrm{R}^{2}=0.8184$ & $\mathrm{R}^{2}=0.8884$ \\
\hline & $y=-3.4348 x 2-5.9874 x+23.21$ & $y=-14.019 x+28.96$ \\
\hline \multirow[t]{2}{*}{ EC } & $\mathrm{R}^{2}=0.9946$ & $\mathrm{R}^{2}=0.839$ \\
\hline & $y=64.161 x^{-9.499}$ & $y=54.169 x^{-8.475}$ \\
\hline \multirow[t]{2}{*}{ Bulk Density } & $\mathrm{R}^{2}=0.8262$ & $\mathrm{R}^{2}=0.845$ \\
\hline & \multicolumn{2}{|l|}{ Subsoil } \\
\hline & $y=142.04 e^{-0.106 x}$ & $y=36960 x^{-2.635}$ \\
\hline Moisture & $\mathrm{R}^{2}=0.7243$ & $R^{2}=0.4653$ \\
\hline EC & $\mathrm{y}=16.851 \mathrm{e}^{-0.889 \mathrm{x}}$ & $y=5.0998 x^{-0.862}$ \\
\hline & $\mathrm{R}^{2}=0.7508$ & $\mathrm{R}^{2}=0.484$ \\
\hline Bulk Density & $\begin{array}{l}y=50.022 x^{-7.31} \\
R^{2}=0.9264\end{array}$ & $\begin{array}{l}y=43.435 x^{-7.685} \\
R^{2}=0.9145\end{array}$ \\
\hline
\end{tabular}

\section{Production of maps for soil properties}

The models obtained were used to produce conjugated moisture, EC and bulk density maps. The regression equations were used to calculate the value of the soil moisture and salinity for each resistivity value of the 40 points of the investigated grid. The calculated moisture and EC values were used to produce conjugate soil moisture and soil-EC maps (Figure 5 and 6).
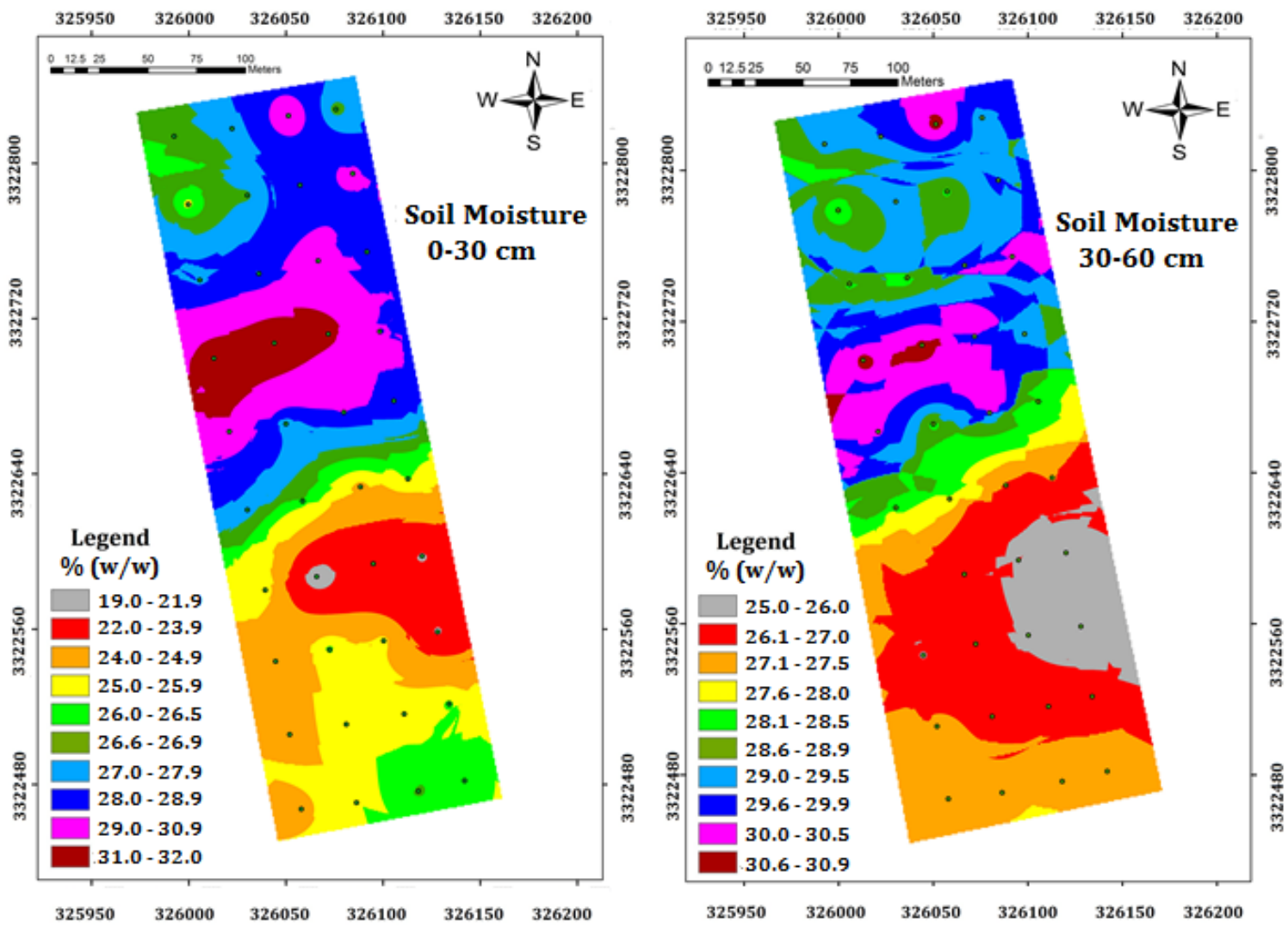

Figure 5. Soil moisture map of top- and subsoils as conjugated from their relevant soil resistivity maps

The spatial dependency of the top and subsoil moisture contents were moderate $(47.5 \%$ and $60.4 \%$, respectively), while it was for soil salinity $68.5 \%$ and $62.5 \%$, respectively as shown in Table 1 . These maps could be used for better management of the farm irrigation system to reduce the uneven distribution of both soil moisture and salinity. Al-Omran et al. (2013) showed in their study on soil spatial variability that only TDS, ESP and OM had weak spatial dependency while other properties had moderate or strong spatial 
dependencies. Huntley (1986) and Michot et al. (2003) concluded that as the resistivity of the pore fluid increased (low salinity) or the porosity decreased, the electrical resistivity of the soil increased.
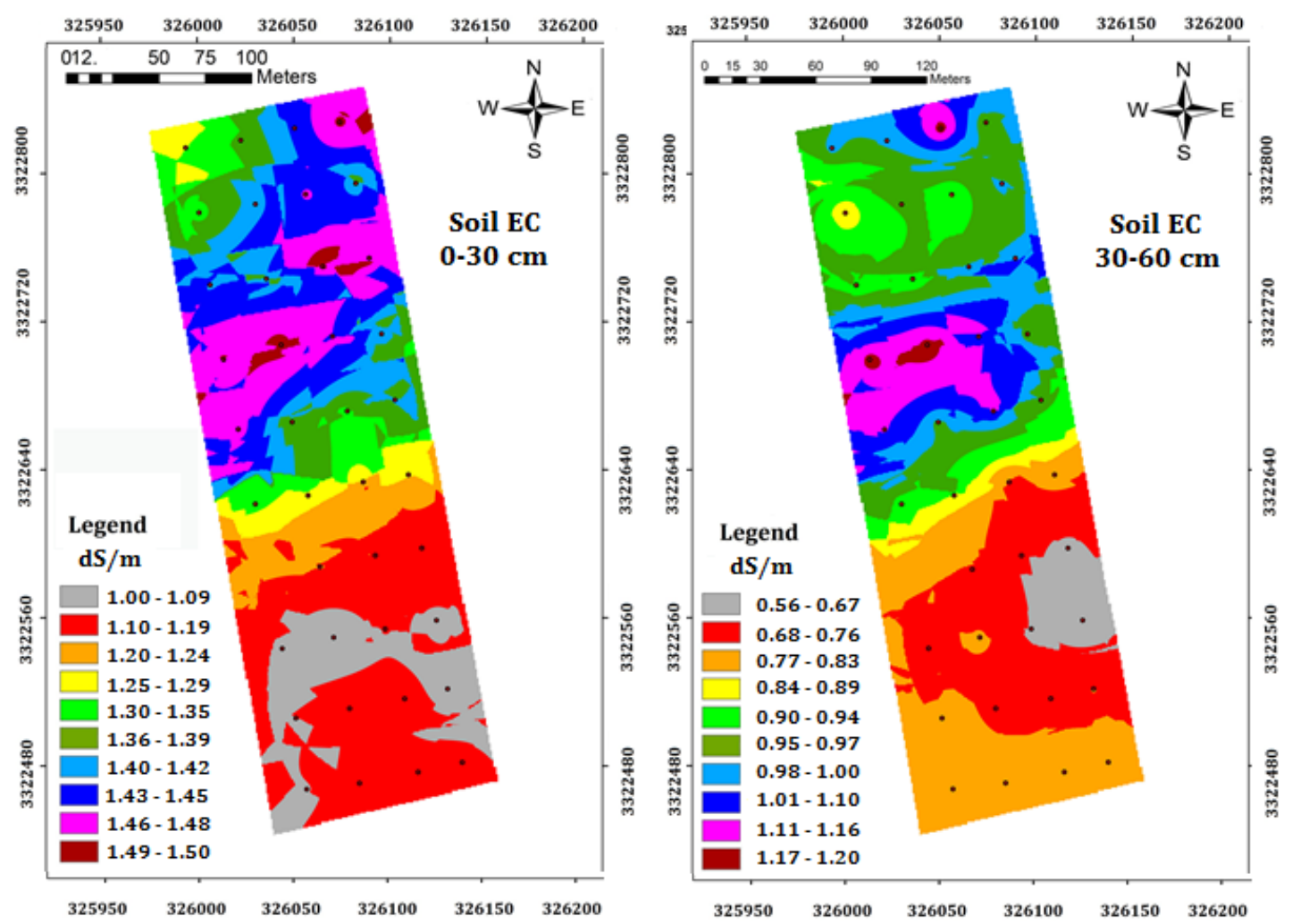

Figure 6. Soil salinity map of top- and subsoil as conjugated from their relevant soil resistivity maps

\section{Conclusion}

In conclusion, mapping of soil electrical resistivity for the surface layer $(0-30 \mathrm{~cm})$ could be used efficiently to express spatial variability of soil properties, especially moisture- salinity content and, to some extent, bulk density without digging. It saves time, effort and money for monitoring the variability of soil moisture and salinity. In addition, soil moisture and salinity maps could be easily produced from resistivity maps and used for soil irrigation management and soil salinity control. With the help of this electrical resistivity method for soil investigation, we can easily analyze the required properties of soil in agricultural fields without disturbing and removing soil samples from its natural condition. Therefore, it is recommended to use this easy mapping of soil electrical resistivity which can facilitate precision or digital agricultural practices, where the heterogeneity and variation of soil physical parameters in a field should be taken into consideration for a successful site specific management.

\section{References}

Abidin, M.H.Z., Ahmad, F., Wijeyesekera, D.C., Saad, R., Baharuddin, M.F.T., 2013. Soil resistivity measurements to predict moisture content and density in loose and dense soil. Applied Mechanics and Materials 353-356: 911-917.

Al-Omran, A.M., Al-Wabel, M.I., El-Maghraby, S.E., Nadeem, M.E., Al-Sharani, S., 2013. Spatial variability for some properties of the wastewater irrigated soils. Journal of the Saudi Society of Agricultural Sciences 12(2) : 167-175.

Besson, A., Cousin, I., Bourennane, H., Nicoullaud, B., Pasquier, C., Richard, G., Dorigny, A., King, D., 2010. The spatial and temporal organization of soil water at the field scale as described by electrical resistivity measurements. European Journal of Soil Science 61(1): 120-132.

Blake, G.R., Hartge, K.H., 1986. Bulk density. In: Methods of Soil Analysis Part 1 Physical and Mineralogical Methods. 2nd Edition, Klute, A., (Ed). American Society of Agronomy, Soil Science Society of America. Madison, Wisconsin, USA. pp. 363-375.

Burger, H.R., 1992. Exploration Geophysics of the Shallow Subsurface. Prentice Hall. New Jersey, USA. 489p.

Bourennane, H., Hinschberger, F., Chartin, C., Salvador-Blanes, S., 2017. Spatial filtering of electrical resistivity and slope intensity: Enhancement of spatial estimates of a soil property. Journal of Applied Geophysics 138: 210-219.

Brillante, L., Bois, B., Lévêque, J., Mathieu, 0., 2016. Variations in soil-water use by grapevine according to plant water status and soil physical-chemical characteristics-A 3D spatio-temporal analysis, European Journal of Agronomy 77: $122-135$. 
Cambardella, C.A. Moorman, T.B., Novak, J.M., Parkin, T.B., Karlen, D.L., Turco, R.F., Konopka, A.E., 1994. Field-scale variability of soil properties in central Iowa soils. Soil Science Society America Journal 58(5): 1501-1511.

Corwin, D.L., Lesch, S.M., Oster, J.D., Kaffka, S.R., 2006. Monitoring management-induced spatio-temporal changes in soil quality through soil sampling directed by apparent electrical conductivity. Geoderma 131: 369-387.

Dabas, M., Tabbagh, A., Boisgontier, D., 2001. Multi-depth continuous electrical profiling (MuCep) for characterization of in-field variability. Proceedings of the Third European Conference on Precision Agriculture. Grenier, G., Blackmore, S. (Eds.), pp. 361-366, 18-21 June 2001 Montpellier, France,

ESRI, 2011. ArcGIS Desktop Software: Release 10. Redlands, CA: Environmental Systems Research Institute.

Gardner, W.H., 1986. Water Content. In: Methods of Soil Analysis Part 1 Physical and Mineralogical Methods. 2nd Edition, Klute, A., (Ed). American Society of Agronomy, Soil Science Society of America. Madison, Wisconsin, USA. pp. 493-544.

Gülser, C., Ekberli, I., Candemir, F., Demir, Z., 2016. Spatial variability of soil physical properties in a cultivated field. Eurasian Journal of Soil Science 5 (3): 192 - 200.

Heiniger, R.W., McBride, R.G., Clay, D.E., 2003. Using soil electrical conductivity to improve nutrient management. Agronomy Journal 95(3): 508-519.

Huntley, D., 1986. Relations between permeability and electrical resistivity in granular aquifers. Ground Water 24(4): 466-474.

Jung, W.K., Kitchen, N.R., Sudduth, K.A., Kremer, R.J., Motavalli, P.P., 2005. Relationships of apparent soil electrical conductivity to clay pan soil properties. Soil Science Society of America Journal 69(3): 883-892.

Kitchen, N.R., Drummond, S.T., Lund, E.D., Sudduth, K.A., Buchleiter, G.W., 2003. Soil electrical conductivity and topography related to yield for three contrasting soil-crop systems. Agronomy Journal 95: 483-495

Kižlo, M., Kanbergs, A., 2009. The causes of the parameters changes of soil resistivity. The 50th International Scientific Conference Power and Electrical Engineering. Proceedings Book. pp.43-46. 14-16 October 2009, Riga, Latvia

Kusim, A.S., Abdullah, N.E, Hashim, Kutty, H.S.B., 2013. Effects of salt content on measurement of soil resistivity. IEEE 7th International Power Engineering and Optimization Conference (PEOCO). pp. 124-128. 3-4 June 2013, Langkawi, Malaysia.

Landrum, C., Castrignanó, A., Zourarakis, D., Mueller, T., 2016. Assessing the time stability of soil moisture patterns using statistical and geostatistical approaches. Agricultural Water Management 177: 118-127.

Lund, E.D., Christy, C.D., Drummond, P.E., 1999. Practical applications of soil electrical conductivity mapping. 2nd European Conference on Precision Agriculture. Proceedings Book. pp.1-9. 11-15 July 1999, Odense, Denmark.

McCutcheon, M.C., Farahani, H.J., Stednick, J.D., Buchleiter, G.W., Green, T.R., 2006. Effect of soil water on apparent soil electrical conductivity and texture relationships in a dryland field. Biosystems Engineering 94(1): 19-32.

Michot, D., Benderitter, Y., Dorigny, A., Nicoullaud, B., King, D., Tabbagh, A., 2003. Spatial and temporal monitoring of soil water content with an irrigated corn crop cover using surface electrical resistivity tomography. Water Resources Research 39(5): 1138-1157.

Omonode, R.A., Vyn, T.J., 2006. Spatial dependence and relationships of electrical conductivity to soil organic matter, phosphorus, and potassium. Soil Science 171(1): 223-238.

Ozcep, F., Tezel, O., Asci, M., 2009. Correlation between electrical resistivity and soil-water content: Istanbul and Golcuk. International Journal of Physical Sciences 4(6): 362-365.

Ozcep, F., Yildirim, E., Tezel, O., Asci, M., Karabulut, S., 2010. Correlation between electrical resistivity and soil-water content based artificial intelligent techniques International Journal of Physical Sciences 5 (1): 47-56.

Pandey, L.M., 2015. Electrical resistivity of sandy soil with water leachates and seawater. Edith Cowan University, Faculty of Health, Engineering and Science, School of Engineering, MSc. Thesis, Australia. 92p.

Panissod, C., Dabas, M., Hesse, A., Jolivet, A., Tabbagh, J., Tabbagh, A., 1998. Recent developments in shallow-depth electrical and electrostatic prospecting using mobile arrays. Geophysics 63(5): 1542-1550.

Rhoades, J.D., 1982. Soluble Salts. In: Methods of Soil Analysis Part 2. Chemical and Microbiological Properties. 2nd Edition, Klute, A., (Ed). American Society of Agronomy, Soil Science Society of America. Madison, Wisconsin, USA. pp. 167-179.

Rhoades, J.D., 1993. Electrical conductivity methods for measuring and mapping soil salinity. Advances in Agronomy 49: 201-251.

Samouëlian, A., Cousina, I., Tabbagh, A., Bruand, A., Richard, G., 2005. Electrical resistivity survey in soil science: a review. Soil and Tillage Research 83(2): 173-193.

Sudha, K., Israil, M., Mittal, S., Rai, J., 2009. Soil characterization using electrical resistivity tomography and geotechnical investigations. Journal of Applied Geophysics 67(1): 74-79.

Sun, B., Zhou, S., Zhao, Q., 2003. Evaluation of spatial and temporal changes of soil quality based on geostatistical analysis in the hill region of subtropical China. Geoderma 115(1-2): 85-99.

Tabbagh, A., Dabas, M., Hesse, A., Panissod, C., 2000. Soil resistivity: a non-invasive tool to map soil structure horizonation. Geoderma 97(3-4): 393-404.

US-EPA, 2019. Resistivity Methods. U.S. Environmental Protection Agency. Available at [Access date : 09.10.2018]: https://archive.epa.gov/esd/archive-geophysics/web/html/resistivity_methods.html 